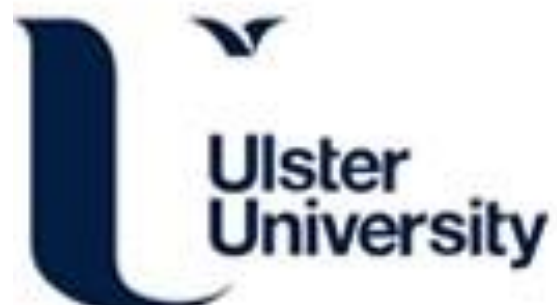

Supernumerary status:definition, operationalisation and its effect in practice

McGowan, B., \& McCormack, B. (2003). Supernumerary status:definition, operationalisation and its effect in practice. Intensive and Critical Care Nursing, 19(5), 308-317. https://doi.org/10.1016/S0964-3397(03)00064-8

Link to publication record in Ulster University Research Portal

\section{Published in:}

Intensive and Critical Care Nursing

Publication Status:

Published (in print/issue): 01/10/2003

DOI:

10.1016/S0964-3397(03)00064-8

\section{Document Version}

Publisher's PDF, also known as Version of record

\section{General rights}

Copyright for the publications made accessible via Ulster University's Research Portal is retained by the author(s) and / or other copyright owners and it is a condition of accessing these publications that users recognise and abide by the legal requirements associated with these rights.

\section{Take down policy}

The Research Portal is Ulster University's institutional repository that provides access to Ulster's research outputs. Every effort has been made to ensure that content in the Research Portal does not infringe any person's rights, or applicable UK laws. If you discover content in the Research Portal that you believe breaches copyright or violates any law, please contact pure-support@ulster.ac.uk. 


\title{
Supernumerary status: definition, operationalisation and its effect in practice
}

\author{
Brian McGowan and Brendan McCormack
}

Brian McGowan MSc, BSc (Hons), DipHE, Cert, ICU Nursing, RSCN, Lecturer in Nursing, University of Ulster, Jordanstown

Room 12L12, University of

Ulster, Shore Road Newtownabbey BT37 OQB, UK. Tel: +44 (0) 28 90366492; Fax: $+44(0) 28$ 90368202; E-mail: brian.mcgowan@ ulster.ac.uk

Brendan

McCormack DPhil

(Oxon), BSC (Hons) Nursing, PGCEA,

RGN, RMN,

Professor of

Nursing

Research/Director

of Nursing

Research and

Development,

Royal Hospitals

Trust, University of

Ulster/Royal

Hospitals,

Grosvenor Road,

Belfast BT12 6BA,

UK

(Requests for

offprints to BMcG)

Manuscript

accepted: 30/06/03

This paper presents an evaluation of the implementation of supernumerary status in intensive care units in the Greater Belfast area. The evaluation focused on three questions, what did staff understand by the term supernumerary status. How was supernumerary status implemented in the Trusts? What effect did supernumerary status have on the staff/Trusts involved? The results of the evaluation are presented here and issues for further development identified.

The study was qualitative in nature and used semi-structured interviews and focus group interviews to collect data. Participants were purposively selected by virtue of their experience of supernumerary status. Interviews and focus groups were audiotaped and transcribed verbatim. These transcripts were then analysed line-by-line and coded. Data analysis described 10 common themes.

In general, the concept of supernumerary status was well received and was supported by all involved who believed that its goal of producing adequately trained and skilled practitioners in an intensive care environment was a worthwhile exercise that benefited both staff and patients.

Overall, exploring the operationalisation of a supernumerary status programme helps us to explore the challenges of supporting neophyte nurses in all areas of practice and challenges service providers to consider creative approaches to providing such support. However, whilst making a positive contribution to the recruitment and development of nurses new to the intensive care environment, further study is required to gauge the long-term effect of this programme on retention of staff.

○ 2003 Elsevier Ltd. All rights reserved.

KEYWORDS: Supernumerary status; Support; Recruitment.

\section{Introduction}

The International Council of Nurses have stated that the quality of health care delivered to

A multi-trust collaborative research project with Royal Group of Hospitals Trust, Ulster Community \& Hospitals Trust, Mater Informorum Trust, and Belfast City Hospital Trust. patients is directly dependent on an adequate supply of qualified nursing personnel (ICN 2000). Concurrently, one should consider that all clinical areas are competing for a limited pool of newly qualified staff. In addition, the Hayes report (2001) argued that with the focus of healthcare delivery shifting to the primary sector, the dependency of patients there would rise. As a result, more highly qualified staff 
would be required in primary care. This creates a problem for tertiary care providers as staff that would have previously had a career in this sector are moving out to the 'community'. This shift has had a knock on effect that has seen the recruitment needs of intensive care units increase. In an attempt to address this and facilitate recruitment to intensive care units, supernumerary status was introduced in 2000 for qualified nurses in the Greater Belfast area.

Gray and Smith (1999) highlighted that as a concept, supernumerary status has been around since the 1950s but was adopted by nurse education in the whole of the UK following the education reforms commonly referred to as Project 2000. In essence, supernumerary status was originally intended to free student nurses from the burden of being treated as cheap labour by transforming their status from that of employee to student. The intention was that whilst still being present in clinical areas and thus being exposed to clinical experience they would not be counted in the numbers of staff present on the ward. However, supernumerary status (as a phrase) has developed negative connotations. This, Lankshear (1998) argued, arose because of differences in interpretation and led to staff on wards making up rules of behaviour that differentiated them from the rest of the staff. This in turn compromised learning opportunities. Downes (2001) concurs with this perspective and states that supernumerary status is part of the problem because staff have interpreted it as meaning that students were only there to observe.

The majority of work about supernumerary status has focused on the role of the student nurse (Parahoo 1992). There was little evidence either in support of or in opposition to the issue with qualified staff. As Charnley (1999) points out, 'the experiences of newly qualified staff are largely unexplored'. This represents a significant gap in the knowledge base that may be addressed by this project.

The purpose of supernumerary status in this context was to attract nurses to work in a specialised area and provide them with an opportunity to build up a repertoire of skills in a supportive environment. In effect, they were being protected from being thrown in at the deep end. Consequently, the study presented here set out to evaluate the development of supernumerary status, determine its impact on practice and provide evidence to facilitate decision making over its further provision.

This paper presents the results of an evaluative study commissioned by the local Health Board to examine the effectiveness of supernumerary status in order to inform further development of the established model. The paper will provide an overview of the methodology used and the study findings. The findings will be integrated with the discussion and focus on answering the key evaluative questions underpinning the study.

\section{Methodology}

\section{Aims}

The evaluation set out to answer three questions:

(1) What did staff understand by the term supernumerary status?

(2) How was supernumerary status implemented in the Trusts?

(3) What effect did supernumerary status have on the staff/Trusts involved?

All the Trusts with intensive care units in the Greater Belfast area $(n=4)$ participated in this study. Agreement from the Directors of Nursing led to the development of an advisory group of senior staff from intensive care units that were to be involved in the study. This group provided expert advice on the intensive care environment, agreed the evaluation questions and advised the participating sample. The participants in the study consisted of people who were affected by supernumerary status and were referred to as 'stakeholders'. Four stakeholder groups were identified:

- Directors of Nursing $(n=4)$;

- Ward managers of the intensive care units $(n=6)$;

- Mentors to supernumerary staff nurses $(n=29)$;

- Supernumerary staff nurses $(n=29)$.

The data collection methods used were focus group interviews and semi-structured interviews. Semi-structured interviews were 
used with the Directors of Nursing and the ward managers as the advisory group felt that this was the most appropriate approach with these particular stakeholder groups. The mentors and the supernumerary nurses formed the focus groups. Robinson (1999) defined focus groups as, 'an in-depth, open-ended group discussion that explores a specific set of issues on a pre-defined and limited topic'. This particular methodology was chosen because the advisory group felt that participants would be more likely to share their experiences as opposed to using a one to one interview technique. Webb and Kevern (2001) supported this view when they stated that, they (focus groups) capitalise on the interaction within a group to elicit rich experiential data'.

A semi-structured interview schedule was used for both individual interviews and focus groups, derived from key themes from the literature and issues raised by the advisory group. Nine focus groups and nine individual interviews were conducted in July-August 2000 and were tape-recorded. Following this, the tapes were transcribed. Content analysis followed transcription. The content analysis involved examining the transcripts line-by-line and noting emerging themes. These themes were then compared and common themes were constructed.

\section{Rigour}

To ensure rigour throughout the study, the development of the research tool (interview schedules) was commented on and revised by the advisory group under the supervision of the Professor of Nursing Research. As the data was being analysed an audit trail was produced so that the research supervisor could concurrently analyse the transcripts and agree or augment the findings.

\section{Ethical approval}

After discussion with the advisory group and the research supervisor, ethical approval from the local research ethics was not sought because no patient involvement was forecast. However, as Parahoo (1997, p. 78) points out, 'There are ethical implications at every stage of the research process'. The ethical issues of this study were addressed by supplying the ward managers with background data so that they could discuss the project with their staff before they agreed to take part in the study. Each participant was written to individually and invited to take part. At this time, they were assured that they had the ability to withdraw at any time and that their identity would not be revealed at any stage. In addition, their 'rights' as participants in research were repeated to them at the start of each focus group before recording began.

Turning up and participating in the focus groups was taken as implied consent to take part.

\section{Findings and discussion}

\section{Question 1: What did staff understand by the term supernumerary status?}

Supernumerary status as a phrase has negative connotations (Lankshear 1998). This, Lankshear argued, arose because of differences in interpretation and led to staff on wards making up rules of behaviour that differentiated supernumerary staff from the rest of the staff. According to Lankshear, this in turn compromised learning opportunities. Consequently, the evaluation presented in this paper focused on participants interpretation and understanding of the term 'supernumerary status'. Two definitional themes were identified.

\section{Additional to the usual complement of staff}

This involved ideas of being extra or not counted in the numbers. Downes (2001) argues that this perspective is part of the problem because staff have interpreted it as meaning that as students (or in this case new staff nurses) were additional to the staff complement they were only there to observe. The ward managers and mentors in this study however dispelled this notion and highlighted that as well as being additional to the staff numbers on the unit, supernumerary nurses were expected to take part in the activities of the ward. This was illustrated by one of the ward managers, who stated, '... Not to be relied 
on to do the basic work although they may contribute to that as well' (WM2).

The supernumerary nurses themselves were not as clear in their definition of supernumerary status. However, their focus was similar to the other stakeholder groups and was illustrated by the comment, 'It is sort of assumed that when you are supernumerary you are not counted in the numbers' (SN1).

The supernumerary nurses highlighted the developmental aspect of supernumerary status, expressed by the comment; 'You weren't counted in the numbers so you're free to do extra learning within the unit' (SN2). Things were not always so clear however and the supernumerary nurses were the only ones who 'faced reality' and admitted that the concept of being supernumerary was not always enforced, this was illustrated by one participant who said, '... but they did rely on you if they were short-staffed. You know if they were short-staffed you know, you sort of had to get on with it' (SN1).

\section{Allocation to a more experienced member of staff for supervision}

The Directors of Nursing (DoNs) explained the allocation concept with the following quote 'They would be assigned a mentor for the duration of their allocation (DN4)'. The ward managers agreed that the supernumerary nurses would be allocated to a more experienced staff member by saying, 'Well, we usually twin them with somebody and they try to have them on the same shifts. Usually a senior experienced member of staff and they work the shift with them' (WM1). Implicit in this theme was the assumption that the new member of staff had 'reduced' responsibilities. The DoNs explained the concept of reduced responsibility by saying, 'A nurse is not relied on solely to deliver care (DN1)'.

In expressing the concept of supervision, the mentors were a little more explicit and stressed that the supernumerary nurse would be carrying out the routine duties of an intensive care nurse but under the guidance of a more experienced member of staff. They do the normal work under supervision with their mentor or another nurse and they're progressing ... they're learning by actually doing the work with experienced ICU nurses' (M2).

Initially the supernumerary nurses concurred with this notion of supervision, 'It was good knowing that I had somebody to ... somebody who would be there if I had any problems and just show me the run of the place and how things were done here' (SN3). However not all of the groups of supernumerary nurses interviewed shared this opinion. One other group suggested that allocation to a mentor was a paper exercise only in that they rarely worked with their mentor. They felt that this led to confusion due to the variability in individual style when carrying out clinical procedures 'I thought it was beneficial being supernumerary but one of the drawbacks was that it depended who you were on with. You're supposed to have one mentor but constraints usually meant that you were with a couple of people and they showed you the skills the way they had learnt it which was not always consistent and then you ended up confused - is this the right way to do it or not?' (SN4). Charnley (1999) underscored the notion of support when she found that a lack of qualified support in clinical practice was a major source of occupational stress for newly qualified staff nurses.

Yassin (1994) however cautioned that on the face of it, providing a mentor may be of benefit to the learner but the complexities and realities of the relationship are unclear and require further research. Northcott (2000) supported this view and argued that mentorship appears to have been applied in a haphazard fashion throughout the profession and warned that the product of inadequate mentorship could be burnout.

\section{Question 2: How was supernumerary status implemented in the Trusts?}

Three themes described the way that supernumerary status had been implemented across the participating Trusts.

\section{A planned and structured programme was offered}

There appeared to be a consensus of opinion that having a planned and structured programme was a fundamental pre-requisite for effectively implementing supernumerary status. The ward managers placed emphasis on assessment and communication between 
the assessors and the assessed which was illustrated by one group who said, '... So we had quite a detailed induction with them into what we expected of them, their progress over the six months and for their mentors the same as well' (WM3). One ward manager summed up the situation when she said, 'it's like a mini intensive care course-what we want our new nurses to have' (WM2).

The supernumerary nurses in one of the focus groups were positive in their assessment of the structured approach by describing their ICU experience thus; 'There was a structured ten weeks you know and maybe ah ... you could have two study days a week and then two and a half days out on the unit and after a few weeks you were able to put two and two together-why you were doing it and learning all your drugs, etc.' (SN2).

All of the units involved, however, did not share this view. Two of the other supernumerary nurse focus groups were critical of implementation with their main criticisms being an apparent lack of structure, direction and theory based classroom time. This can be summarised by the following excerpt from supernumerary nurse group 1 (SN1):

We thought that it was a good idea if you worked with someone constantly and you were always shadowing them and then in the middle two months you would maybe be able to look after a patient on your own, but not a very sick patient. Then in the last couple of months of the supernumerary phase you were rather broken in to looking after more seriously ill patients. (SN1)

\section{Variable assessment criteria}

This theme reflected an abandonment of the structured approach to supervision and the adoption of an ad hoc approach to assessments. It could be argued that the structured assessment transformed into a rite of passage or an initiation based on staff perception and socialisation. This was highlighted by one ward manager who said "You know it's a matter of we'd have a chat. The mentor and the new nurse would have their chat. I as Sister, or one of the other Sisters would have a chat with the nurse, 'Do you feel that you would be comfortable doing this?"' (WM2). One could argue that the previous question from the ward manger was a loaded question and the response options open to the staff member would in that case be limited. Additionally a 'chat' could be seen as a euphemism for managerial control in which the flow of information was one sided with little scope for staff input.

The mentors also described a less structured approach with little mention of learning outcomes or objectives having been set that the supernumerary nurse had to achieve. This was demonstrated by one group who said: 'I think we just discuss it really, you know, what we have achieved so far and what we've covered so far and what we would like to cover a bit more or maybe see a bit more but I think, here, it's not very organised, it's not like written criteria as such' (M4).

One of the other mentor groups however was able to describe a more structured approach to assessment,

We did have an evaluation like ... sort of forms to complete. What we did was we all sat down and looked at things that she wanted to go over or wanted to specifically learn about and then what goals we were going to do, you know, achieve this and then the action when we carried it out, you know, certain days we say well lets have a look at our plan ... like we haven't gone over the CVP monitor and the setting up of the line and we'll do that today and you know, the next time she would have done it herself and I would have checked over it so that sort of how we went about assessing things and if she had any concerns then she would always say to me, you know, how she felt or .... (M3)

The supernumerary nurses had mixed experiences of assessment ranging from structured and recorded to the rite of passage experience identified above. Overall, it appeared that wide varieties of approaches to assessment were employed with a consequent variation in standards and degree of satisfaction. The extent to which this affected the nurse's performance remains to be explored. Another issue that remained unclear was what would happen to those staff who failed to meet prescribed standards, i.e. it was unclear what would happen to staff who failed to complete competencies. An area that, it could be argued, is vital to address when basing training on competencies, procedures and accumulation of knowledge. 


\section{Length of time as a supernumerary nurse}

The length of time one spent as a supernumerary nurse had been prescribed by the Health Board as being six months. There were, however, a variety of experiences here ranging from a feeling that the full six months as prescribed was necessary, to stating that as little as four weeks was on offer in one unit. Overall, though, it appeared that most respondents felt that six months was too long with the consensus being, that perhaps a shorter period (three/four months) would be adequate. This was best described by one of the supernumerary nurses who said, 'because I trained longer - three months probably would have been enough for me. But for newly qualified staff I think six months would be good for them' (SN1).

Yassin (1994) suggested that supernumerary status could actually be a barrier to learning and contribute to the theory-practice gap because supernumerary staff do not become completely integrated into the clinical environment until this period has finished. Thus, a reduction in the supernumerary period would appear to be a positive step in trying to achieve the optimum benefit from this supportive practice whilst offsetting the drawbacks that exist. In any event, whilst the supernumerary nurses expressed the opinion that six months was too long it appeared that actually being supernumerary was the exception rather than the rule.

Overall, it appeared that supernumerary status had been implemented in a variety of ways that depended upon the particular working practices and customs of the unit involved. It could be argued that this ad hoc approach to implementation would ultimately be damaging to the staff because of the confusion that this approach would engender.

\section{Question 3: What effect did supernumerary status have on the staff/Trusts involved?}

\section{Supernumerary status attracts staff to work in intensive care}

The Directors of Nursing were keen to point out that implementation of supernumerary status had (to an extent) solved some of their recruitment problems and had gone some way to address retention problems also. This notion was captured by one DoN who said, 'It has been an excellent recruitment tool. We had major difficulties in the past recruiting to Intensive Care. With supernumerary status, we no longer have vacancies within our Intensive care unit. Invariably these people stay. I think that staff recognise that if they want to improve their staffing levels that this is something that needs to happen' (DN1).

The mentors focused upon the fact that as time progressed the supernumerary nurses clinical abilities improved and as a result, their ability to share the workload increased. This was captured by one group of mentors who said:

Well there have been positive effects on the unit from a selfish point of view because it has given us more numbers, more girls, and even though you have to mentor them and you are supervising them (especially in the later stages of their supernumerary status) when they have been there maybe three or four months when they are really at the stage when they could have patients themselves. They are still not counted in the numbers but you have maybe two or three extra people in the morning who know fairly well what they are doing. (M1)

The supernumerary nurses highlighted the fact that the offer of support from supernumerary status was a major motivator in their decision to apply to work in intensive care. This was validated by one supernumerary group who said:

Personally I thought I couldn't come just qualified you know, and straight into intensive care without that. I wouldn't have even applied for the job if I never thought I was going to get that support and back up. (SN1)

The majority of respondents felt that the initiative was worthwhile with the net gain being that experienced staff who stay in intensive care are worth the effort required to produce them. The Directors of Nursing were cognisant that such an initiative was useful but pointed out that continuing support from commissioning bodies such as Health Boards was required. The ward managers pointed out that the investment was worthwhile and recognised that it was not a quick fix but a medium to long-term solution to an insidious problem. This premise was highlighted by one 
group of ward managers who said, 'You are investing a lot of time and energy into these people and you can see the potential benefit then at the end of the six months and so that is good' (WM3).

Marquis (1988) warned however that offering more to new staff to work in places such as ICU sets precedents and as a result, more will be expected. Consequently, a failure to provide supernumerary status in the future (now that a precedent has been set) may have serious ramifications for future recruitment.

\section{The stress of supernumerary status}

Whilst respondents agreed that supernumerary status had attracted staff, they were mindful of the fact that it represented an additional responsibility for the existing staff that were already under considerable stress. Whilst working in an already busy intensive care unit, nursing staff were expected to also act as mentors to new nurses. This meant an additional work expectation as teachers, assessors, counsellors, and role models. These additional roles, Barrett and Myrick (1998) suggested contributed to work overload and thus the amount of stress experienced by mentors.

The mentors interviewed in this study, concurred with this view by highlighting that supernumerary status added to their stress levels. This was explained by one ward manager who said, 'To have a six month programme is, $A$, stressful for the mentors of the supernumerary nurses, $B$, stressful for the other staff in the unit because there are so many new staff here and $C$, again that's diluting and increasing your team so it affects your team spirit and morale because they always have someone working with them and they're not sure of their abilities' (WM3).

The mentors also highlighted the stressful nature of supernumerary status but appeared to take the responsibility seriously. This was validated by one group of mentors who said:

It was good but it was tiring as well. You know if you had the same person for a couple of months it was good to build up a relationship with them and know them but it was also quite tiring to have somebody with you all the time. If you're mentoring somebody quite often whenever they're only at the beginning it can take double the time so if you have a busy patient and you know you're going to have a busy day sometimes it can be quite stressful having to repeat everything for a second time or explain everything you're doing so it takes twice as long. Sometimes you feel under pressure to know everything ... to know the answer to everything. Sometimes it can be stressful if every time that you're on the person is with you if you're ever having problems. (M2)

Overall, though, the mentors felt that the extra effort required was justified in that ultimately they were preparing someone who could share their workload and make a positive contribution to the unit.

It's very rewarding when you have been with someone for a length of time and you can see that they have come on in what they're doing or they're able to question things ... it's rewarding. (M2)

The extent to which this was communicated to the supernumerary nurses remains in question though as they appeared to express the opinion that they felt they were resented. This was revealed by one group of supernumerary nurses who said:

It's never been in the unit before you know. People were wondering why we actually needed this. Really, there was a bit of resentment but I think it was because it was just so new. You know, it was a new concept really. (SN1)

\section{Confidence and competence}

The respondents felt that supernumerary status provided an excellent framework for support and education, which enabled supernumerary nurses to develop their confidence and competence in intensive care nursing. They felt that this benefited patients and positively affected the quality of care delivered by creating skilled practitioners. This was explained by one mentor who said:

I think it gives you a very confident six-month newly qualified staff nurses honestly. I think that they feel more confident in their work ... certainly more than a girl that has come in without that status, without that training 
wouldn't be as confident after six months as these girls appear to be. (M1)

The supernumerary nurses identified the development of their confidence in carrying out their role and felt that supernumerary status gave them the ability to identify their limitations and practice safely, this was described by one supernumerary nurse who said, 'It was a lot easier being supernumerary than actually just coming in and not having any supernumerary status. I just felt a bit more confident because you knew there was somebody there supporting you and you weren't just being thrown in at the deep end. Its allowed people to develop at their own rate you know. It gives you that time to settle in, find your feet and build up a bit of confidence' (SN2).

However not all supernumerary nurses shared this positive experience with one group pointing out that what was proposed did not always match up to what occurred in practice. This was highlighted by one supernumerary nurse who said:

When I first came here I was told I would be supernumerary for six to seven weeks and it ended up I was left to my own devices. It sort of confuses you and you're sort of thinking, "maybe they think I'm competent enough to do that" but then maybe they're just leaving me because they're short-staffed or whatever? So you never really knew where you stood and not having any feedback was another drawback, you never really knew where you were. (SN4)

In summary, it appeared that supernumerary status had an overall positive effect on the units involved. However further research is needed to explore in more depth the stress experienced by other staff arising from supporting supernumerary nurses.

\section{Issues arising}

Overall, this study described 10 themes emerging from a series of focus groups concerning the definition, operationalisation and effect of supernumerary status in intensive care units in the Greater Belfast area.

Whilst making a positive contribution to the recruitment and development of nurses new to the intensive care environment further study is required to gauge the long-term effect on retention of staff. Murray (1988) in a study examining the work variables influencing job satisfaction and turnover carried out in New Jersey concluded that fringe benefits had no effect on a nurses decision to stay in a job. However, it could be argued that supernumerary status represents the development of a supportive clinical learning environment which is an intrinsic factor contributing to job satisfaction and not a fringe benefit. Hart and Rotem (1995) defined a clinical learning environment as one that contributed to professional development and was made up of several factors. These factors orbited professional development and were described as autonomy and recognition, job satisfaction, role clarity, quality of supervision, peer support and opportunities for learning. Field (1999) reported on a programme of support that improved nurse recruitment, retention, and the two main facets of that programme were: a comprehensive support system and structured development opportunities. From this it can be seen that several of the above factors are also component parts of the current supernumerary status initiative in intensive care units. Dunn and Burnett (1995) point out however that these factors are interactive and do not exist in isolation of one another. Consequently, the provision of any future programme would have to ensure that all of the factors were being addressed.

In tandem with the design of the programme, there is also a requirement for comprehensive preparation of supernumerary status nurse mentors. Throughout the course of the interviews held with the mentors there was little evidence to suggest that mentors were formally trained to carry out the duties of a mentor in this context. Indeed the evidence seemed to suggest that selection of mentors was based on their position in the 'pecking order' and the ability to effectively mentor a neophyte intensive care nurse was not taken into consideration. In addition, the extent to which the ward managers had been prepared for the implementation of the programme was unclear. Yassin (1994) cautions that the experience and attitude of the ward sister will influence how concepts are interpreted and 
applied at a local level. In general, the concept of supernumerary status was well received and was supported by all involved who believed that its goal of producing adequately trained and skilled practitioners in an intensive care environment was a worthwhile exercise that benefited both staff and patients.

However, from the data in this evaluation, it would appear that a four-month supernumerary period is sufficient for most staff and may prevent the barriers to learning earlier identified by Yassin (1994). Because of the variation in the way the programme has been implemented, common standards to underpin the programme need to be developed, including the defining of outcomes and development of a common supervision and mentorship framework The literature suggests that competence is difficult to assess (Watson et al. 2002) and the data from this evaluation would certainly support this view. Key to the assessment is the issue of the experience of mentors and the training required by them to perform their rolesomething that was not addressed by this programme. Overall, however, exploring the operationalisation of a supernumerary status programme helps us to explore the challenges of supporting neophyte nurses in all areas of practice and challenges service providers to consider creative approaches to providing such support. This view is supported by Gerrish (2000) who demonstrated that new nurses who were supported through the first six months post qualification by a preceptorship programme experienced less stress than those who did not have that opportunity.

\section{Conclusion}

This evaluation has helped to identify issues that need to be considered in supporting neophyte nurses in any setting. The importance of preparing the environment, support for mentors and access to a standardised programme has been identified. Whilst supernumerary status is an important part of nursing development further work is needed to demonstrate the actual benefits to nurses and patients.

\section{Acknowledgements}

We would like to acknowledge the following people without whom the project would not have been realised. Mrs. M. Waddell, Director of Nursing, Eastern Health \& Social Services Board; Professor S. Salmon, Director of Nursing, Ulster Community \& Hospitals Trust; Mrs. I. Foster, Deputy Director of Nursing, Ulster Community \& Hospitals Trust; Mrs. D. O'Brien, Director of Nursing, Royal Group of Hospitals Trust; Mrs. A. McCabe, Director of Nursing, Belfast City Hospital Trust; Mrs. M. Hinds, Director of Nursing, Mater Informorum Hospital Trust; Ms. E. Allen, Secretary, Ulster Community \& Hospitals Trust. Advisory Group members: Sr. G. Fulton, advised on behalf of Ulster Community \& Hospitals Trust; Sr. J McCormick, advised on behalf of Royal Group of Hospitals Trust; Sr. M. Chapman, advised on behalf of Royal Group of Hospitals Trust; Sr. L. McAlea, advised on behalf of Mater Informorum Hospital Trust; and Mrs. A. McCracken, advised on behalf of Belfast City Hospital Trust.

\section{References}

Barrett C, Myrick F 1998 Job satisfaction in preceptorship and its effect on the clinical performance of the preceptee. Journal of Advanced Nursing 27(2): 364-371

Charnley 1999 Occupational stress in the newly qualified staff nurse. Nursing Standard 13(29): 32-36

Downes M 2001 Support for student training: a new role as demonstrators. Nursing Times 97(7): 39

Dunn SV, Burnett P 1995 The development of a clinical learning environment scale. Journal of Advanced Nursing 22: 1166-1173

Field A 1999 Starters orders. (Development programme for newly qualified nurses in a Birmingham Trust to improve retention). 17 June 109: 26-27

Gerrish K 2000 Still fumbling along? A comparative study of the newly qualified nurse's perception of the transition from student to qualified nurse. Journal of Advanced Nursing 32(2): 473-480

Gray M, Smith L 1999 The professional socialisation of diploma of higher education in nursing students (Project 2000): a longitudinal qualitative study. Journal of Advanced Nursing 29(3): 639-647

Hart G, Rotem A 1995 The clinical learning environment: nurses perceptions of professional development in clinical settings. Nurse Education Today 15: 3-10

Hayes M 2001 Acute Hospitals Review Group Report. DHSSPS-NI

ICN 2000 Nurse retention, transfer and migration. Nursing Standard 14(36): 33 
Lankshear A 1998 Helping students find a place in the team. Nursing Times 94(29): 64-65

Marquis B 1988 Attrition: the effectiveness of retention activities. Journal of Nursing Administration 18(3): $25-29$

Murray KH 1988 Intrinsic, Extrinsic and Contextual Work Variables Influencing Job Satisfaction/Turnover Among Registered Nurses in Selected New Jersey Hospitals. Seton Hall University School of Education Northcott N 2000 Mentorship in nursing. Nursing Management 7(3): 30-32

Parahoo K 1992 Perceptions of supernumerary status. Nursing Standard 6(50): 37-40

Parahoo K 1997 Nursing Research: Principles, Process and Issues. Palgrave Macmillan, London
Robinson N 1999 The use of focus group methodologywith selected examples from sexual health research. Journal of Advanced Nursing 29(4): 905-913

Watson R, Stimpson A, Topping A 2002 Clinical competence assessment in nursing: a systematic review of the literature. Journal of Advanced Nursing 39(5): 421-431

Webb C, Kevern J 2001 Focus groups as a research method: a critique of some aspects of their use in nursing research. Journal of Advanced Nursing 33(6): 798-805

Yassin T 1994 Exacerbation of a perennial problem? The theory practice gap and changes in nurse education. Professional Nurse 10(3): 183-187 